Instructions for authors, subscriptions and further details:

http://brac.hipatiapress.com

\title{
Arte y Ciencia para un Paisaje en Crisis: Caso de Estudio del Proyecto Cartografías de la Metamorfosis \\ Pedro Ortuño Mengual ${ }^{1}$
}

1) Departamento de Bellas Artes, Facultad de Bellas Artes. Universidad de Murcia.

Date of publication: February $3^{\text {rd }}, 2021$

Edition period: October 2020 - February 2021

To cite this article: Ortuño Mengual, P. (2021). Arte y ciencia para un paisaje en crisis: caso de estudio del proyecto Cartografías de la Metamorfosis. Barcelona, Research, Art, Creation, 9(1), pp. 29-44. doi: 10.17583/brac.2021.6311

To link this article: http://dx.doi.org/10.17583/brac.2021.6311

PLEASE SCROLL DOWN FOR ARTICLE

The terms and conditions of use are related to the Open Journal System and to Creative Commons Attribution License (CC-BY). 
BRAC - Barcelona Research Art Creation. Vol. 9 No. 1, January 2021, pp. 29-44

\section{Art and Science for a Crisis Landscape: Case Study of the Cartographies of Metamorphosis Project}

Pedro Ortuño Mengual

Departamento de Bellas Artes, Facultad de Bellas Artes. Universidad de Murcia.

(Received: 3 August 2020; Accepted: 8 December 2020; Published: 3 February 2021)

\section{Abstract}

Based on Ehrenfried Pfeiffer's method of sensitive crystallization, the Cartographies of Metamorphosis artistic project exposes the vitality, in the form of mandala graphics, of the different horticultural products from Campo de Cartagena, a method that makes the intrinsic quality of the material visible organic. In 2016, the Mar Menor landscape collapsed for the first time and accentuated its state of environmental crisis, due in part to the dumping of large amounts of organic matter and nutrients of various kinds, but especially from agricultural and livestock activities. Made in the context of the environmental crisis of the Mar Menor, the sculptural and audiovisual installation metaphorically reflects on the new geological era coined by Paul Crutzen and the eutrophication landscape around the lagoon.

Keywords: Art and science, cartography, anthropocene, art and ecology, landscape, Mar Menor 
BRAC - Barcelona Research Art Creation. Vol. 9 No. 1, January 2021, pp. 29-44

\section{Arte y Ciencia para un Paisaje en Crisis: Caso de Estudio del Proyecto Cartografías de la Metamorfosis}

Pedro Ortuño Mengual

Departamento de Bellas Artes, Facultad de Bellas Artes. Universidad de Murcia.

(Recibido: 3 agosto 2020; Aceptado: 8 diciembre 2020; Publicado: 3 febrero 2021)

\section{Resumen}

A partir del método de cristalización sensible de Erhenfried Pfeiffer, el proyecto artístico Cartografías de la metamorfosis expone la vitalidad, en forma de grafismos mandálicos, de los diferentes productos hortícolas del Campo de Cartagena, un método que permite hacer visible la calidad intrínseca de la materia orgánica. En el 2016 el paisaje del Mar Menor colapsó por primera vez y acentuó su estado de crisis medioambiental, debido en parte, al vertido de grandes cantidades de materia orgánica y nutrientes de diversa naturaleza, pero sobre todo de la actividad agraria y agropecuaria. Realizado en el contexto de deterioro del medio natural, la instalación escultórica y audiovisual reflexiona metafóricamente sobre la nueva era geológica acuñada por Paul Crutzen y el paisaje de eutrofización del entorno de la laguna.

Palabras clave: Arte y ciencia, cartografía, antropoceno, arte y ecología, paisaje, Mar Menor 


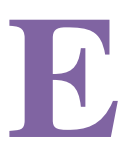

1 presente artículo analiza el proyecto artístico Cartografías de la metamorfosis (2020) realizado en el contexto de la crisis medioambiental del Mar Menor de Cartagena. Se trata de una instalación escultórica y audiovisual que reflexiona metafóricamente sobre el paisaje agrícola del entorno de la laguna y cómo los flujos energéticos de los productos hortícolas biodinámicos, pueden ser una solución al colapso del medio natural de la zona.

La cristalización sensible descubierta por el químico alemán Erhenfried Pfeiffer entre los años 1924 y 1930 a partir el análisis de productos agrícolas mezclados sobre una placa de Petri con una disolución de cloruro de cobre, es un método por el cual podemos ver las propiedades cualitativas y energéticas de cualquier sustancia orgánica (Tesson y Fernandez-Bravo, 2000). Nos sirve para registrar visualmente, la energía vital de los alimentos. En nuestro mundo contemporáneo los métodos globales, cualitativos o sensibles, están marginados por una comunidad científica preocupada tan solo por el elemento cuantitativo. La cristalización sensible necesita investigadores que efectúen investigaciones, de las que no se ve de inmediato el valor o el impacto (Pla, 1996, p.22). Saber si una sustancia tiene una calidad suficiente con respecto a lo que se puede esperar de ella (el pan) por ejemplo, debe alimentar, pero el pan que comemos ¿nos alimenta realmente?

Los alimentos con los que nos nutrimos argumenta Carlos Pla Descarrega, están constituidos por materia física, química y tangible, los podemos ver, tocar, oler y saborear pero para saber más de ellos hay que ir a un laboratorio y analizar las proteínas, glúcidos, lípidos etc. En el Universo existen otras leyes que dinamizan las sinergias de todos estos principios inmediatos contenidos en los alimentos; leyes que no pueden determinarse desde el punto de vista químico ni analítico de un laboratorio, ya que hacen referencia a las energías, a la vida contenida en cada alimento y a las fuerzas que componen la materia viviente en su morfología más profunda. Es aquí donde nace el método de la cristalización sensible, "que mide la potencia y la naturaleza de las fuerzas formadoras de la materia orgánica" (p.22), las imágenes obtenidas no expresan analíticamente una reacción química, sino que nos muestran "la materialización de unos campos de fuerza".

El proceso de cristalización sensible de un producto hortícola consta de dos etapas (p.23), la primera es el resultado de verter una solución de Cloruro de cobre en una placa de Petri, de las utilizadas en laboratorios de microbiología, introducida en un ambiente de temperatura y humedad constante para evitar contaminaciones. Si el producto analizado proviene de 
agricultura biodinámica, pasadas unas 12 horas, podremos observar cómo la sal del cloruro de Cobre $(\mathrm{C} 12 \mathrm{Cu})$, cristaliza creando formas mandálicas organizadas. Por el contrario, si el producto proviene de la agricultura industrial o de una agricultura a la que se le han añadido componentes químicos, las formas obtenidas están rotas, desorganizadas. La segunda etapa según este investigador, consiste en un análisis e interpretación de los resultados. En este sentido Marie Francoise Tesson consiguió codificar esta lectura de imágenes a partir de conceptos iniciales basados en el principio de antroposofía de Rudolf Steiner, donde las imágenes se observan desde una polaridad de fuerzas suprasensibles. Desde esta perspectiva, las sustancias agroalimentarias, aparecen como unas energías de fuerza de vida que se oponen a cualquier sustancia inerte o sin vida (Tesson y Fernandez-Bravo, 2000).

A partir la observación de estructuras mandálicas realizadas con la técnica de la cristalización sensible, de productos provenientes de invernaderos y terrenos de agricultura biodinámica del Campo de Cartagena, obtuvimos imágenes armónicas que ilustran los flujos energéticos entre el Mar Menor y los destinos finales de estas hortalizas. El arte, la ciencia y la tecnología se aúnan para imaginar la forma de la energía que recorre nuestros cuerpos, así como las diversas formas en las que pasa en nosotros y "a través de" nosotros. Como afirma Albert Einstein:

Saber que detrás de cada experiencia de la vida hay algo que escapa a nuestro entendimiento, cuya belleza sublime no captamos más que indirectamente, nos hace maravillarnos e intentar captar humildemente, aunque sea solo una imagen de la estructura grandiosa de todo lo que existe. (Einstein, 1930, p.12)

\section{Metodología}

La metodología utilizada en el proyecto está inspirada en los planteamientos del libro Walkscapes: El andar como práctica estética de Francesco Careri (2013). El andar es un acto cognitivo y creativo capaz de transformar simbólica y físicamente tanto el espacio natural como el antrópico. La intención de andar por el Campo de Cartagena para recorrer y cartografiar los cultivos biológicos y biodinámicos, recuperar las huellas del pasado, hablar con sus gentes, reconstruir la historia de lo cotidiano. Para Walter Benjamin en su Crónica de Berlín, caminar por la ciudad supone transitar un lugar para la evocación de recuerdos de su infancia y juventud (Benjamin, 2004). Esta idea de andar planteada por Careri, ha permitido pensar y construir un mundo 
propio que "oscila entre la memoria, lo real y lo imaginario". La obra resultante presenta una estética diferente en la que se imbrica la poesía visual y el concepto reivindicativo. Se puede apreciar la belleza de las formas mandálicas biodinámicas como metáfora de una extraña metamorfosis que culminará con la desestructuración de las apariencias de la agricultura industrial. Todas estas imágenes cartografían doblemente lo energético, por ello se han combinado con otras donde se aprecia un desplazamiento de la cámara siguiendo el recorrido de recolectoras de productos hortícolas en el interior de un invernadero, junto con imágenes de archivo de la zona, donde se aprecia por ejemplo, animales en la recolecta del campo o un metraje en Súper 8 de personas bañándose en la laguna en el inicio del boom turístico de los 70’s. De esta manera cada escena se convierte en una carta geográfica energética y bella que surge de los campos del Mar Menor, como manifiesto de la recuperación ambiental del mismo.

Preferimos una metodología cualitativa haciendo hincapié en la fórmula de observación participante. De acuerdo con esta definición, el proyecto se desarrolló a partir de la observación, de hacer recorridos por el campo de Cartagena durante un periodo de dos años (2018-2019). Los sociólogos Becker y Geer entienden por observación participante como:

(...) aquel modelo en el cual el observador participa en la vida cotidiana de la gente que está siendo objeto de estudio (...) observando las cosas que ocurren, escuchando lo que se dice y haciendo pregunta a la gente durante un periodo de tiempo determinado. (Becker y Geer, 1958, p.39)

\section{Discusión}

El Mar Menor es una laguna costera situada en la Región de Murcia. Ha generado un enclave medioambiental con una flora y fauna características que dotan al paisaje de gran belleza alrededor del cual se forjó su particular idiosincrasia: la pesca tradicional, la extracción de la sal y los balnearios al amparo de unas aguas tranquilas y poco profundas. En el 2016 la laguna colapsó por primera vez y acentuó su estado de crisis medioambiental, debido en parte, al vertido de grandes cantidades de materia orgánica y nutrientes de diversa naturaleza, pero sobre todo de la actividad agraria y agropecuaria. Más tarde, en septiembre de 2019, el efecto de lluvias torrenciales de Depresión Aislada en Niveles Altos (DANA), hizo que la laguna salada volviera a colapsar por segunda vez, con la eutrofización de sus aguas. Como explica la bióloga Francisca Giménez Casalduero: 
Igual que ocurre con las lechugas, los nitratos de la agricultura que llegan a la laguna empezaron a hacer crecer las algas y el fondo se cubrió de un césped de Caulerpa. Esto es un primer síntoma de eutrofización: el cambio de fondos de plantas fanerógamas a fondos dominados por este tipo de alga a causa del exceso de nutrientes. (...) La entrada de nitratos hace crecer de forma exponencial el fitoplancton hasta que la densidad de células en el agua es tan grande que no deja pasar la luz. Como resultado, la vegetación por debajo de tres metros no puede hacer fotosíntesis y muere. La descomposición llevada a cabo por las bacterias provoca anoxia (ausencia de oxígeno), lo que acaba con toda la fauna a esa profundidad. (Álvarez, 2020)

Este ejemplo de colapso ambiental a causa de la actividad humana, puede darnos indicios de que estamos entrando en un nuevo tiempo geológico acuñado por Paul Crutzen y Eugene Stoermer (2000) como Antropoceno. El autor considera que la acción del comportamiento humano sobre la Tierra en los últimos años, ha constituido una nueva era geológica provocando cambios en el ciclo del agua, desequilibrios, destrucción en los ecosistemas marinos y terrestres, aumento de fenómenos meteorológicos extremos, acidificación de los océanos, desaparición de los bosques etc. Zalasiewicz menciona también, que los cambios en los ciclos del carbono, el nitrógeno o el fósforo provocados por el uso de pesticidas, tendrán repercusiones en la composición de los estratos terrestres (Zalasiewicz, 2019). El tiempo es un elemento central en la conceptualización del Antropoceno, nos conduce a considerar una temporalidad biológica y geológica en un mundo que se mueve dentro de un presente estrecho (Trischler, 2017).

Por un lado, el proyecto Cartografías de la metamorfosis está basado en el método de las "cristalizaciones sensibles" descubiertas por Pfeifer, que considera las granjas como organismos complejos haciendo hincapié en la interrelación entre suelos, plantas y animales, tratados en su conjunto como un sistema en equilibrio. De esta forma persigue como objetivo, equilibrar la disposición de nutrientes debido a la salida de las cosechas fuera de la finca, con la producción de elementos nutritivos mediante la cría de animales y el cultivo de otras plantas, aumentando así la polinización. Por otro lado, ofrece la posibilidad de reflexionar sobre la agricultura biodinámica como solución medioambiental al problema de crisis que se encuentra sumido el entorno y ecosistema del Mar Menor. 

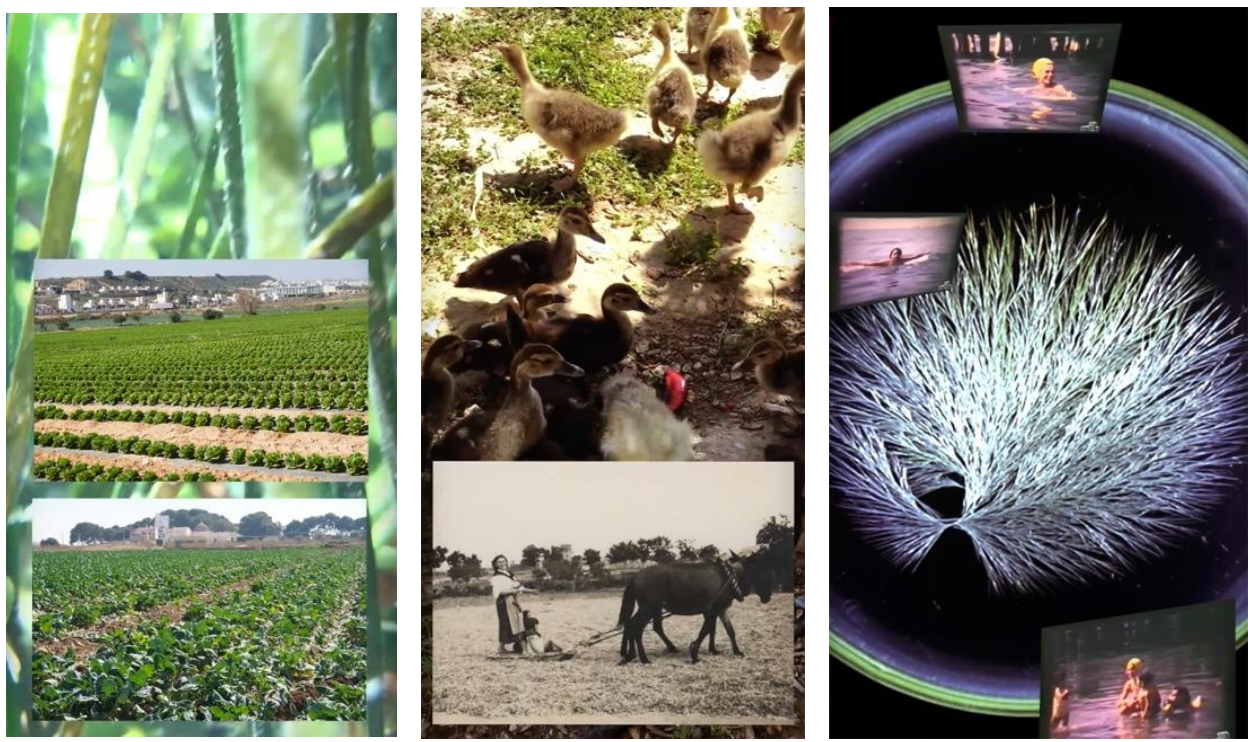

Imagen 1. Imágenes del vídeo Cartografía de la metamorfosis donde se aprecia las formas mandálicas de la cristalización sensible, así como imágenes de archivo superpuestas sobre cultivos del Campo de Cartagena.

En la actualidad la mayor parte de la agricultura en la zona, proviene de la agricultura industrial de cultivo intensivo, centrada en la producción masiva con un alto nivel de tecnificación (León y Bellido, 2016, p.319). Es crucial de esta forma una inversión de capital, energía y otros derivados químicos. Esta agricultura, como su nombre indica, aprovecha intensivamente la tierra porque se cultiva hasta tres veces al año. Utiliza fertilizantes, pesticidas químicos, maquinaria y sistemas de riego complejos y necesita de menos tierra para producir una misma cantidad de alimento que el obtenido en la agricultura convencional.

A raíz de las sucesivas crisis medioambientales, la agricultura biodinámica se está abriendo paso de manera exponencial en el Campo de Cartagena, siendo este tipo de agricultura ecológica más respetuosa con el medio. Diversos estudios demuestran que la agricultura biodinámica crea biodiversidad en los campos de cultivo enriqueciendo de manera natural los nutrientes. Pensamos que si se implantase este tipo de cultivo, desaparecerían gran parte de los problemas medioambientales. 
El clima templado propio de la Región ha propiciado que el entorno costero haya experimentado un fuerte desarrollo económico, principalmente debido a la sobreexplotación descontrolada. Esta situación, unida a otros factores de orden económico, político y medioambiental como argumenta el biólogo Ángel Pérez-Ruzafa, han llevado a la laguna a un alarmante estado de deterioro: "La entrada de nutrientes a través de los cursos de agua superficiales al Mar Menor se ha caracterizado ampliamente durante los últimos años, siendo una de las principales consecuencias de la agricultura intensiva que se lleva a cabo en el área circundante" (León y Bellido, 2016, p.320). El Antropoceno muestra contundentemente sus efectos en la zona. Según el Informe de Síntesis sobre su estado actual publicado en 2019 a raíz de la crisis eutrófica de 2016 "han forzado el cambio del sistema, originalmente oligotrófico, a un estado eutrófico, el cual define un enriquecimiento en nutrientes inorgánicos más allá del nivel crítico de la capacidad autorreguladoras de un sistema determinado".

En este contexto, es necesario pensar colectivamente un nuevo relato para la laguna a partir de la confrontación de sus distintos imaginarios: reclamo turístico, huerto productivo, depósito de vertidos, espacio deportivo, resort, oasis natural, sistema complejo de materia híbrida en el que se amalgaman naturaleza y artificio, biología y tecnología, tradición y progreso. A través de la articulación de saberes y la colaboración interdisciplinar, el proyecto Cartografías de la metamorfosis propone utilizar la capacidad del arte contemporáneo y las prácticas de la visualidad como vehículo para imaginar colectivamente el futuro del Mar Menor.

Los recientes hallazgos de una columna de sedimentos de 39 centímetros de las marismas de Urdaibai, España, que contiene hidrocarburos aromáticos policíclicos que registra la contaminación generada en los últimos setecientos años, se suma a las pruebas tangibles que apoyan la idea de que el ser humano ha entrado en una nueva época geológica: el Antropoceno (Leorri et al, 2014).

Los inicios del Antropoceno son aún materia de amplio debate (Ruddiman, 2005; Brown, 2014; Leorri et al, 2014). Algunos científicos señalan a la agricultura extensiva y tecnificada como la causa original (Ruddiman, 2005), mientras que otros son partidarios de que se inició en la Revolución Industrial, a mediados del siglo XVIII. Algunos dudan de que los gases emitidos en los últimos doscientos años hayan sido suficientes para cambiar el clima. Desde este punto de vista, estamos en los orígenes del Antropoceno porque lleva tan solo doscientos años, si lo comparamos con los cuatro mil quinientos años que tiene la tierra y los doscientos mil años de nuestra especie. Según FernándezDurán (2010) se han propuesto tres fases para una posible caracterización de 
este nuevo concepto; la primera de ellas con el surgimiento de la agricultura en el Neolítico, una segunda fase con la Revolución Industrial y por último la tercera, con la Gran aceleración industrial después de la Segunda Guerra Mundial o hasta 1945 con la detonación de la primera bomba atómica el lunes 6 de agosto de 1945 y con ello el comienzo de la era nuclear.

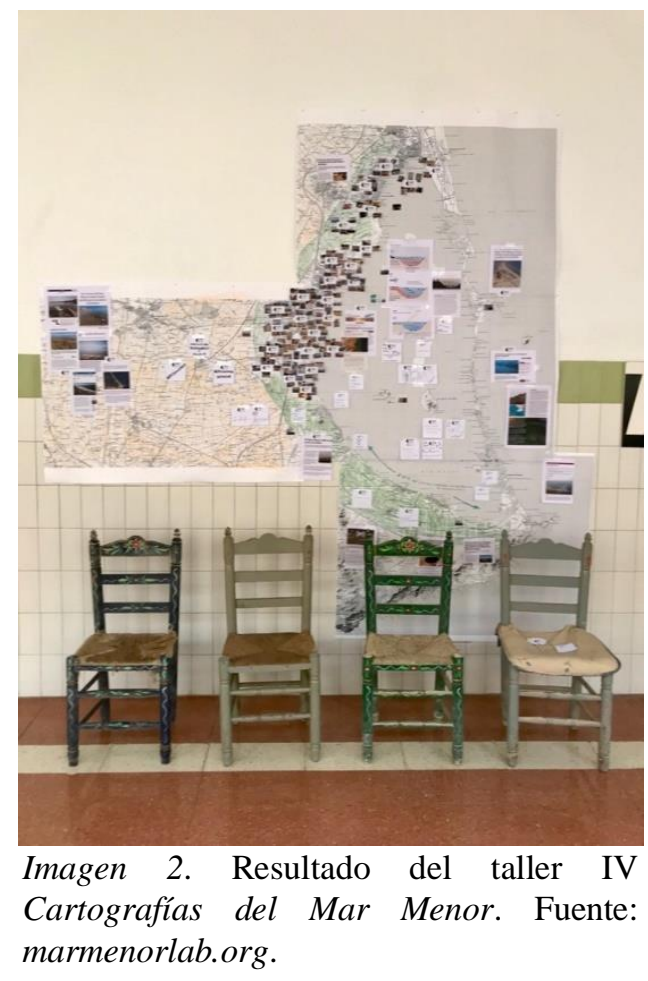

\section{Antropoceno y Arte Contemporáneo}

Respecto a acciones de arte contemporáneo que se vienen realizando sobre este tema, observamos que en 2011, en Ushuaia (Argentina), tuvo lugar la tercera edición de la Bienal del Fin del Mundo, que se proponía vincular el arte contemporáneo con el medio ambiente bajo el lema "Antropoceno". En esta misma línea José Manuel Bueso plantea ¿Por qué resulta más fácil imaginar el Fin del Mundo que el fin del Capitalismo?, el autor observa que las estructuras narrativas centradas en el Fin del Mundo, han venido desplazando a las que giraban en torno al Fin del Capitalismo, desconectando el deseo de transformación social radical de la idea de revolución, y 
reconduciéndolo hacia la retórica de la catástrofe y el colapso civilizatorio (Bueso, 2019). Unos años más tarde, en octubre de 2015 en Les Abattoirs de Toulouse en Francia, se organizó un coloquio y una exposición con el título The Anthropocene Monument. La excusa de diseñar un monumento para el Antropoceno llevó a reunir a un conjunto de pensadores y artistas para debatir sobre el significado de esta nueva época. La exposición fue comisariada por Bruno Latour y Bronislaw Szerszynski.

Dos años más tarde, en octubre de 2017 se inauguró en Barcelona en Centro de Cultura Contemporánea (CCCB) una exposición titulada Después del fin del mundo. Aunque esta exposición no contenía en su título el término "Antropoceno" en la descripción sobre la misma se hace referencia inequívoca al concepto: nuestro planeta se habría transformado irreversiblemente en el "planeta Antropoceno". La exposición buscaba, entre otros objetivos, explorar la llegada al mundo de la segunda mitad del siglo XXI y la responsabilidad de nuestra sociedad para con las generaciones que nacerán y crecerán en dicho mundo. En esta misma línea, José Luis Albelda (2019) en su artículo La belleza circular, nos habla de la necesidad de la importancia del cambio social y de conciencia radical:

Nosotros somos los hijos del petróleo y de los bits, pero hemos de educar una nueva generación discípula del sol y de la permacultura. Toda una revolución del imaginario que no se basta con ajustes de sistema por parte de la ciencia y la tecnología -con su quimera del desarrollo sostenible-, sino que necesita un cambio de conciencia radical, similar al que tuvo lugar en las revoluciones sociopolíticas del siglo pasado. (p.15)

Más recientemente en 2018, desde Canadá, The Anthropocene Project se presentaba como un trabajo multidisciplinar que combina las artes plásticas, el cine y la realidad aumentada junto con la investigación científica de biólogos y antropólogos, con la finalidad de estudiar la influencia humana en el estado, dinámica y futuro de la Tierra. Como uno de sus resultados más destacables, el proyecto mostró unos de los primeros documentales sobre el concepto de Antropoceno, realizado por Jennifer Baichwal y titulado Anthropocene: The Human Epoch.

Desde la Universidad de Murcia, a partir de un proyecto de Investigación I+D+i de la Fundación Daniel \& Nina Carasso (2017-2020), coordinado por Clara Boj y Pedro Ortuño, se creo el grupo de trabajo abierto y transdisciplinar Reset: Mar Menor: Laboratorio de imaginarios para un paisaje en crisis (http://www.marmenorlab.org). Una de las actividades de este grupo fue la 
exposición Lagunas; Proyectos y procesos del arte y ciencia en el Mar Menor (2019) comisariada por Clara Boj y Diego Días en el Centro Puertas de Castilla de Murcia, donde desde una perspectiva de arte, ciencia y tecnología, se mostraron los trabajos de artistas que abordan la precariedad en la que se encuentra el ecosistema marino.
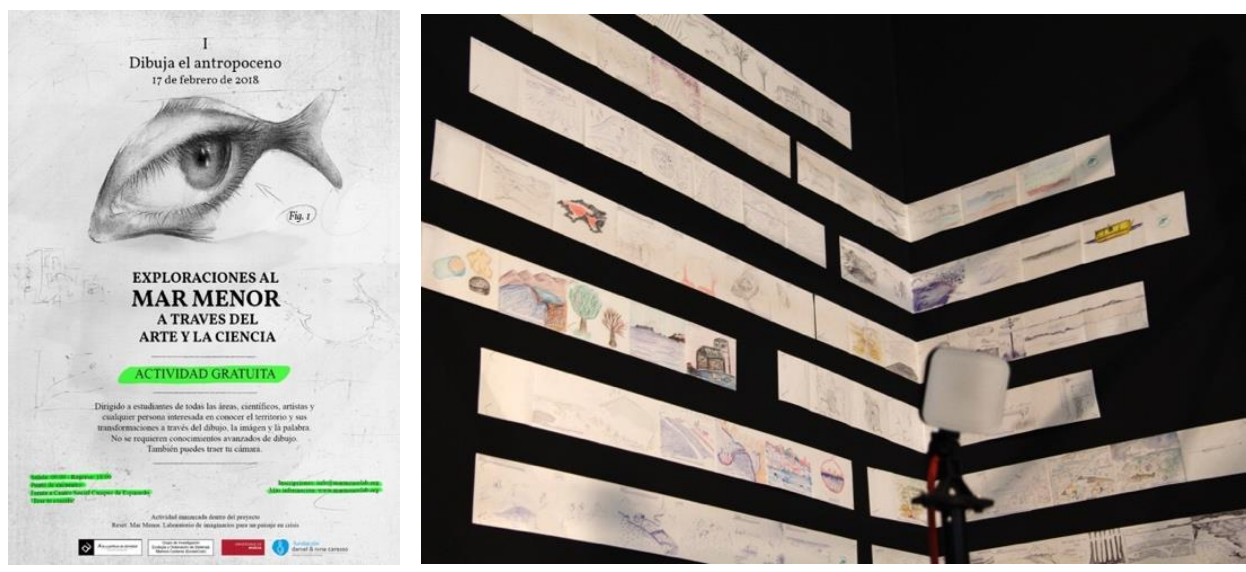

Imagen 3. Cartel de actividad y dibujos Exploraciones al Mar Menor a través del arte y la ciencia. Fuente. marmenorlab.org.

Una de las obras presentadas tuvo que ver con dibujos exploratorios realizados por los participantes de dos exploraciones a través del arte y la ciencia, la primera de ellas Dibuja el Antropoceno y la segunda Dibuja el Capitaloceno. La idea fue conocer de cerca la situación a través del dibujo como práctica de observación y conocimiento del territorio. Visitamos, para ello, distintos sistemas extractivos que confluyen en la laguna costera (la agricultura intensiva, el turismo, el negocio inmobiliario, entre otros) con el fin de comprender cómo afectan al estado de este paraje natural. El dibujo es nuestra principal herramienta ya que nos permitió registrar información por medio de la observación. Posteriormente para el análisis, planteamos una serie de actividades que ayudaron a experimentar y entender el contexto y a proyectarlo de otra manera.

El grupo lanzó también dos convocatorias de proyectos artísticos (2018 y 2019) con la idea de implicar a artistas de renombre internacional como Christina Stadlbauer (AU), Paul Sermon, Jeremiah Ambrose \& Charlotte Gould (UK) y el colectivo Boredomresearch (UK). En la exposición de 
Murcia se presentó el proyecto Cartografía de la metamorfosis (2019) de Pedro Ortuño objeto de estudio en este artículo.

\section{Contexto y Entorno}

Clemente Álvarez (2020) argumenta que la laguna se encuentra en crisis. En la actualidad constituye un ecosistema único de agua salada, con cinco islas volcánicas en su interior y una biodiversidad singular, pero también un caso de cómo el desprecio al medio ambiente se vuelve contra los humanos. Para el catedrático de biología Ángel Pérez-Ruzafa al igual que José Luis Albelda (2019) plantean la necesidad de un cambio radical en pro de preservar el medioambiente:

Es imprescindible cortar de manera inmediata la entrada de agua dulce a la laguna salada para recuperar su estabilidad, ya sea con infraestructuras útiles, como con medidas relacionadas con el cambio en la agricultura y dejando claro que si hay actividades insostenibles, hay que hacerlas sostenibles, para todo lo cual hay capacidad, pero hace falta «voluntad». (Guillén, 2019)

El paisaje del Mar Menor comenzó a transformarse con la urbanización de La Manga, cuando el abogado Tomás Maestre Aznar logró convertirse en dueño de la estrecha lengua de arena entre la laguna salada y el Mediterráneo, entonces un paisaje salvaje, casi sin tocar. Antes estaba en manos de su propia familia y otros herederos del negocio de la minería, considerándose en aquella época de poco valor. Pero gracias a sus contactos con el franquismo, consiguió que esa tierra mínima fuese uno de los emplazamientos elegidos por el régimen para levantar una nueva industria, la del turismo. Así fue cómo el arquitecto catalán Antonio Bonet, que había trabajado en París con Le Corbusier, recibió el encargo de diseñar en aquel lugar mágico, en mitad de la nada, una zona turística de lujo que atrajera a visitantes extranjeros. Con el fin del franquismo y la crisis del petróleo de 1973, el proyecto de La Manga empezó a hacer aguas. Para afrontar las deudas, comenzó a pagar con solares a proveedores, albañiles, fontaneros. El desarrollo de La Manga no solo inauguró en la zona un modelo de urbanismo excesivo, sino que también tuvo un impacto determinante sobre el propio interior de la laguna (Álvarez, 2020).

El trasvase Tajo-Segura que fue otra obra monumental que transformaría la agricultura en el Campo de Cartagena y marcaría el futuro de este ecosistema. Lo que antes eran campos de secano comienzan a regarse, añadiendo fertilizantes, con un efecto a kilómetros de distancia. En cuanto a 
las causas de la crisis del Mar Menor, el informe elaborado por científicos del Instituto Español de Oceanografía (IEO), de la Universidad de Alicante, de la Universidad Politécnica de Cartagena y de la Fundación Nueva Cultura del Agua, destaca que la laguna recibe desde la década de 1980 grandes cantidades de materia orgánica y nutrientes procedentes de vertidos de diversa naturaleza, entre los que se encuentran las aguas residuales urbanas y, sobre todo, los flujos contaminantes tanto difusos como puntuales, procedentes de la actividad agraria y agropecuaria del Campo de Cartagena. Como afirman León y Bellido (2016) en este estudio:

En el caso del Mar Menor los impactos derivan fundamentalmente de las presiones derivadas de la agricultura intensiva del Campo de Cartagena, una alta presión urbanística, el turismo de temporada, las actividades recreativas y episodios de lluvias torrenciales que facilitan el transporte de contaminantes asociados a los suelos de la agricultura y de la minera. (p.318)

\section{Resultados y Conclusión}

Se ha reflexionado y escrito mucho acerca de cómo el paisaje Mar Menor ha dejado de ser un lugar estable para convertirse en un lugar cambiante y en declive muy similar a otras regiones que están sufriendo las consecuencias del cambio climático. Esta doble faceta de espacio ambiental, ecología y recuerdo, han sido utilizadas por artistas, comisarios y grupos de investigación para vincular el arte contemporáneo con el medio ambiente.

Es bien es conocido a través de los medios de comunicación, la situación de precariedad que sufre el entorno del Campo de Cartagena debido a la sobreexplotación agraria y turística. Los mapas son una imagen estática a la cual se le escapa la permanente mutabilidad y cambios al que están expuestos los territorios. En este artículo se ha descrito una situación que conduce a un paisaje en crisis del Mar Menor, puede que a muchos de nosotros estas descripciones nos evoque también aspectos, memorias y situaciones que no aparecen en los mapas pues no contemplan la subjetividad de los procesos territoriales, sus representaciones simbólicas o los imaginarios que sobre ellos se crean. Son las personas que habitan en los lugares quienes realmente crean y transforman los territorios, los modelan desde el diario transitar y percibir y crear. Al igual que las líneas de costa cambian en función de las mareas y su representación cartográfica es incierta e imprecisa, los mapas son representaciones incompletas del territorio en cuanto que este no es solo espacio sino también lugar, tiempo, memoria y habitar. 
El proyecto Cartografías de la Metamorfosis trata un nuevo escenario, donde a través de imágenes de cristalización sensible de productos hortícolas del campo de Cartagena, ofrece la posibilidad de reflexionar sobre la agricultura biodinámica como solución medioambiental al problema de crisis que se encuentra sumido el ecosistema marino.

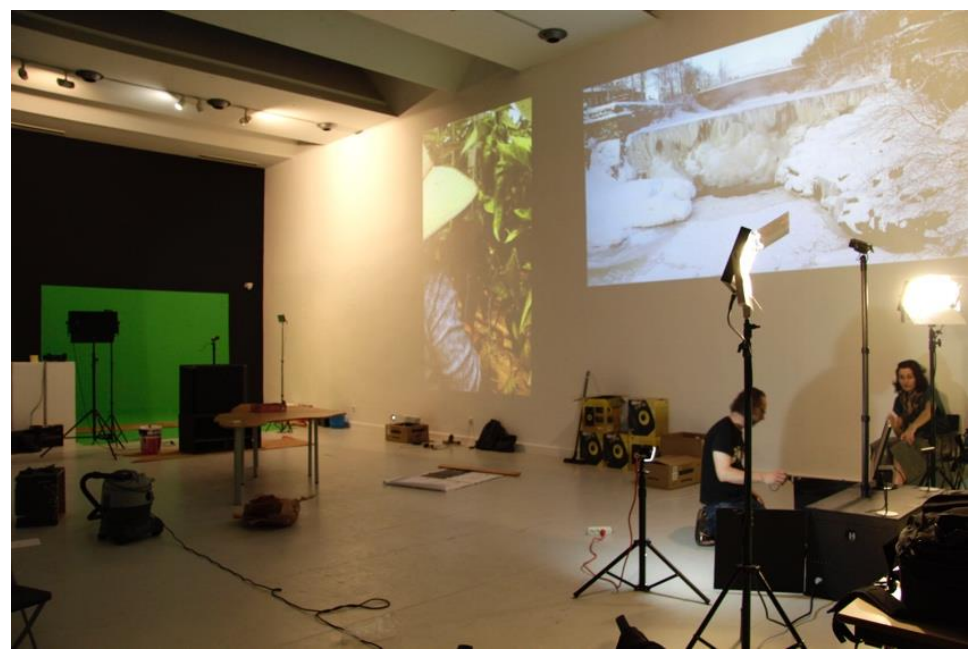

Imagen 4. Exposición Lagunas; Proyectos y procesos del arte y ciencia en el Mar Menor donde se aprecia el proyecto Cartografías de la Metamorfosis.

El presente texto nace en el marco de un proyecto 13-AC-2017'Reset Mar Menor: Laboratorio de Imaginarios para un Paisaje en Crisis' financiado por la Fundación Daniel \& Nina Carasso

\section{Referencias}

Albelda Raga, J. L. (2019). La belleza circular. Arte y Políticas de Identidad, 20. https://doi.org/10.6018/reapi.385621

Álvarez, C. (2020). Entrevista a Gimenez-Casalduero. F. en diario El País. Mar Menor, cuando el desprecio al medio ambiente se vuelve contra nosotros. (23.02.2020)

Becker, H. S \& Geer, B. (1958). Participant observation and interviewing: a rejonder. Human Organization (17).

Benjamin, W. (2004). El libro de los pasajes. Edición española de Rolf Tiedemann. Madrid: Akal. 
Brown, G. H. (2014). The anthropocene: A geomorphological and sedimentary view, en R. Rocha et al. (eds.), strati 2013. Springer Geology (pp. 909-914).

Bueso, J. M. (2019). Teotwawki y otros dioses neoliberales. Arte y Políticas de Identidad, 20, 49-80. https://doi.org/10.6018/reapi.389481

Careri, F. (2013). Walkscapes: el andar como práctica estética. Barcelona: Gustavo Gili.

Crutzen, P. J. (2002). Geology of Mankind. En Nature, vol. 415, núm. 6867, p. 23.

Crutzen, P. J. y Stoermer, E. F. (2000). The Anthropocene. Global Change Newsletter, 41, pp.17-18.

Einstein, A. (1930). El mundo como yo lo veo. Barcelona: Plutón ediciones (2017).

Fernández Durán, R. (2010). El Antropoceno: la crisis ecológica se hace mundial. La expansión del capitalismo global choca con la biósfera. Madrid: Pelegrina. http://estudiosdelaener.

Guillén, Z. (2019). Pérez Ruzafa lamenta que no se haya hecho nada concreto por revertir la situación del Mar Menor. Diario la Verdad (18.10.2019). https://www.laverdad.es/murcia/cientificos-lamentanconcreto-20191018132028-nt.html

Kaplan, J. O., Krumhardt, K. M., Ellis, E. C., Ruddiman, W. F., Lemmen, C. y Goldewijk, K. K. (2011). Holocene carbón emissions as a result of anthropogenic land cover change. The Holocene, 21: 775-791.

León, V.M y Bellido, J.M. (2016). Mar Menor: una laguna singular y sensible. Evaluación científica de su estado. Madrid: Instituto Español de Oceanografía.

Leorri, E., Mitra, S., Irabien, M. J., Zimmerman, A. R., Blake, W. H. y Cearreta, A. (2014). A 700 year record of combustion-derived pollution in northern Spain: Tools to identify the Holocene/ Anthropocene transition in coastal environments. Science of The Total Environment, 470-471, pp.240-247.

McClure, S. B. (2013). Domesticated animals and biodiversity: Early agricultura at the gates of Europe and long-term ecological consequences. Anthropocene.

Pla, C. (1996). Cristalizacón sensible. Gea (17), 10-12.

Ruddiman, W. F. (2005). Calentamiento antropogéncio preindustrial. Investigación y Ciencia, 344, pp.2-39. 
Tesson, M.F y Fernandez-Bravo M.G. (2000). Cristaux sensibles. Contribution théorique et pratique à une science du vivant. Paris: Editions du Fraysse.

Trischler, H. (2017). El Antropoceno, ¿un concepto geológico o cultural, o ambos? En Destacados (54), pp.40-57.

Zalasiewicz, J. (2019). The Anthropocene as a Geological Time Unit.

Cambridge: Cambridge University Press.

https://doi.org/10.1017/9781108621359

Pedro Ortuño: Doctor y profesor en el área de escultura del Departamento de Bellas Artes de la Facultad de Bellas Artes de la Universidad de Murcia. Artista visual e investigador.

Email address: pedrort@um.es

Contact Address: Facultad de Bellas Artes, Campus de Espinardo S/N. Espinardo. 30100 Murcia. 